\title{
Das Recht der Industriellen Revolution
}

\author{
Hrsg. v. Matthias Maetschke, David von Mayenburg u. Mathias Schmoeckel
}

[The Law of the Industrial Revolution.]

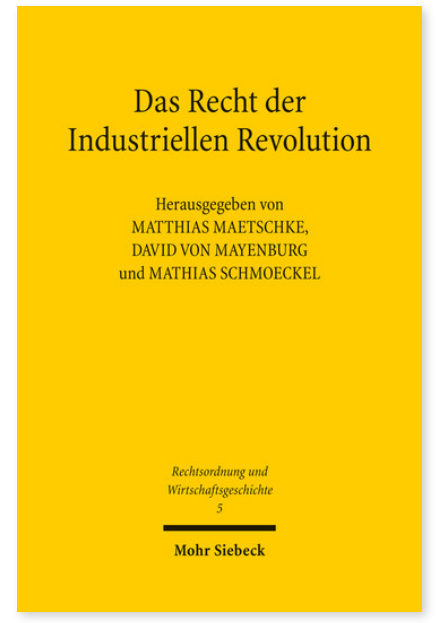

2013. VIII, 265 pages. ROWG 5

ISBN 978-3-16-152703-6

sewn paper $64,00 €$

ISBN 978-3-16-160610-6

eBook PDF $64,00 €$
Published in German.

Using case studies and studies of problems as examples, the authors of this volume show how legal reforms created the basis for industrialization and influenced its structure. In doing so, they examine the close connection between economic and legal history during this time.

\section{Survey of contents}

Mathias Schmoeckel: Einleitung: Die industrielle Revolution als Produkt einer neuen Rechtsordnung - Matthias Maetschke: Recht, Wettbewerb und Industrialisierung. Die rechtlichen Rahmenbedingungen der Industrialisierung in Preußen und Deutschland (1807 bis 1873) - Florian Dressel: Die wechselseitige Beeinflussung von Patentrecht und industrieller Entwicklung - Der Einfluss privater Interessengruppen - David von Mayenburg: Apollinis und Apollinaris - Das deutsche Reichsgericht und der Weltmarkt für Mineralwasser im ausgehenden 19. Jahrhundert - Johannes Rüberg: Der Konkurrenzkampf der Netze: Die Entstehung des Telegraphenwegegesetzes von 1899 - Markus Patt: Der »Misserfolg« des preußischen Eisenbahngesetzes von 1838 - Von mangelnder Rechtssicherheit bei der gesetzlichen Zulassung der Eisenbahnaktiengesellschaft - Philipp Büsch: Recht und leitungsgebundene Energie - Die langfristigen Auswirkungen des sachenrechtlichen Einflusses auf die Errichtung elektrischer Netze zu Beginn des 20. Jahrhunderts - Miroslava Totseva: Eine »Revolution« der Prinzipien? Die Geburt des Arbeitsvertragsrechts im letzten Drittel des 19. Jahrhunderts - Christopher Scholz: Übernahme-, Konsortialverträge und Anleihebedingungen: die rechtliche Gestaltungsfreiheit der Banken bei der Unternehmensfinanzierung durch Anleihen bis zum Beginn des 20. Jahrhunderts - Sebastian Keding: Bankenaufsicht im 19. Jahrhundert als repressives Eingriffsmittel? - Die Einführung einer Aufsichtspflicht über die Hypothekenbanken im 19. Jahrhundert unter Berücksichtigung ihrer ideengeschichtlichen Grundlagen - Meike Kilian: Das Gesetz über die privaten Versicherungsunternehmungen von 1901. Von der Kompetenz zum Gesetz: 34 Jahre Stillstand? - Marek Steffen Schadrowski: Information als Wirtschaftsgut? Nachrichtenagenturen im 19. Jahrhundert im Spannungsfeld zwischen freiem Markt und staatlicher Regulierung am Beispiel von »Wolffs Telegraphisches Bureau«

Matthias Maetschke Geboren 1976; Studium der Rechtswissenschaften an den Universitäten Frankfurt/Main und Bonn; 2006 Promotion; 2008 Zweites juristisches Staatsexamen; Rechtsanwalt im Bereich des privaten Immobilienwirtschaftsrechts in Düsseldorf; seit 2009 Akademischer Rat auf Zeit am Institut für Deutsche und Rheinische Rechtsgeschichte der Universität Bonn; 2015 Erteilung der venia legendi für Bürgerliches Recht, Deutsche Rechtsgeschichte und Historische Rechtsvergleichung.

David von Mayenburg ist Professor für Rechtsgeschichte und juristische Zeitgeschichte (Extraordinariat) an der Universität Luzern.

Mathias Schmoeckel Geboren 1963; Studium der Rechtswissenschaft in Bonn, Genf und München; 1993 Promotion; 1999 Habilitation; Geschäftsführender Direktor des Instituts für Deutsche und Rheinische Rechtsgeschichte und Bürgerliches Recht, sowie des Rheinischen Instituts für Notarrecht. https://orcid.org/0000-0003-1504-4228

Order now:

https://www.mohrsiebeck.com/en/book/das-recht-der-industriellen-revolution-9783161527036?no_cache=1 order@mohrsiebeck.com

Phone: +49 (0)7071-923-17

Fax: +49 (0)7071-51104 